\title{
Detonation effects of shallow buried explosive in sandy soil on target plate acceleration in a small-scale blast test
}

\author{
Zulkifli Abu Hassan*, Aniza Ibrahim and Norazman Mohamad Nor \\ National Defence University of Malaysia, Sungai Besi Camp, 53100 Kuala Lumpur, Malaysia
}

\begin{abstract}
Small-scale blast tests were carried out to observe and measure the influence of sandy soil towards explosive blast intensity. The tests were to simulate blast impact imparted by anti-vehicular landmine to a lightweight armoured vehicle (LAV). Time of occurrence of the three phases of detonation phase in soil with respect to upward translation time of the test apparatus were recorded using high-speed video camera. At the same time the target plate acceleration was measured using shock accelerometer. It was observed that target plate deformation took place at early stage of the detonation phase before the apparatus moved vertically upwards. Previous data of acceleration-time history and velocity-time history from air blast detonation were compared. It was observed that effects of soil funnelling on blast wave together with the impact from soil ejecta may have contributed to higher blast intensity that characterized detonation in soil, where detonation in soil demonstrated higher plate velocity compared to what occurred in air blast detonation.
\end{abstract}

\section{Introduction}

Vehicles that operate in conflict zones are susceptible to landmine or IED threats. Explosive shock front from detonation of landmine could damage the vehicle and the impact could also cause bodily injuries due to vehicle floor board deformation and acceleration [1]. Preventing casualties or reducing severe injuries and ensuring the safety of the occupants require necessary measures which include developing protective systems for both the vehicle and personnel.

Physical damage and degree of impairment caused by detonations of buried mines vary when the explosion takes place in different type of soils. Depending on soil types and conditions, when shallow buried explosive is detonated, the impact delivered to the above ground object or structure impart distinct intensity of blast loading. This has been observed in numerous experimental works [2] [3] [4] [5] that were carried out to investigate the phenomenon. Properties and conditions of the soil that are crucial in causing variation of magnitude and intensities of blast loads have been identified and presented in many documented researches. Soil properties and conditions such as moisture content, particle size distribution, density and depth of burial (DoB) of the explosive charge are reported to be key dependent factors in causing variations in blast intensity of a landmine explosion [6] [7].

In order to develop optimal design of protective systems against landmine blast, accuracy of finite elements model simulations is crucial. Finite elements model validation, and improved data gathered from experimental tests based on specific type of soils and conditions would enhance simulation capability. In this study, small-scale blast tests have been carried out using portable tests apparatus to measure the effect of in-situ sandy soil on shallow buried explosive blast intensity. Target plate acceleration was measured using shock accelerometer and high-speed video camera was used to record the movements of the apparatus during the tests. This paper presents the finding of experimental tests of the blast loading from detonation of shallow buried explosive on target plate acceleration with correlation to detonation phase of explosion in soil.

\section{Test apparatus}

The apparatus is modelled at a 1/10th scale (scale factor 10) to represent the undercarriage dimension and weight of an armoured vehicle. The underside dimension of the apparatus however, is made into a square shape instead of rectangular, total weight of the apparatus is about 21.74 $\mathrm{kg}$, it consists of a steel jig and a target plate.

As shown in Figure 1, the main structure of the test jig is made up of a C-section mild steel structural channel with $100 \mathrm{~mm}$ web x $56 \mathrm{~mm}$ flange x $5 \mathrm{~mm}$ thickness. Four pieces of the C-section mild steel members are welded and bolted together to form a $500 \mathrm{~mm}$ x $500 \mathrm{~mm}$ square frame that leaves a square opening of $390 \mathrm{~mm}$ side in its centre. A sacrificial steel target plate of $500 \mathrm{~mm} \times 500$ $\mathrm{mm} \times 5 \mathrm{~mm}$ is attached at the bottom side of the frame.

* Corresponding author: zulabha@yahoo.com 


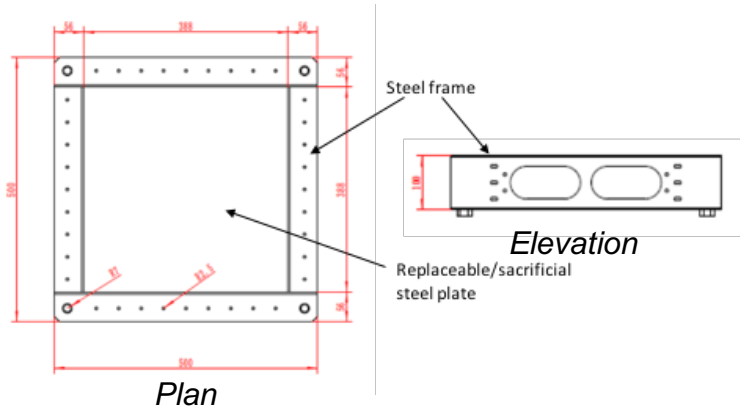

Fig. 1. Schematic drawing of a steel frame

\section{Explosive charge}

Each of the blast tests in this experiment was conducted by detonating the mass of $20 \mathrm{~g}$ AN Emulsion High Explosive commercial grade explosive charge. The charge assembly is shown in Figure 2.

\begin{tabular}{|l|l|}
\hline Component & Specifications \\
\hline \multirow{5}{*}{ Explosive charge } & $20 \mathrm{~g} \mathrm{AN} \mathrm{Emulsion} \mathrm{H} \mathrm{E}$ \\
& $\begin{array}{l}\rho=1.13 \mathrm{~g} / \mathrm{cc}-1.24 \mathrm{~g} / \mathrm{cc} \\
\text { VOD }=4500-5500 \mathrm{~m} / \mathrm{s} \\
\text { Expl. energy }=2.85 \mathrm{MJ} / \mathrm{kg}\end{array}$ \\
\hline \multirow{2}{*}{ Detonator } & $\begin{array}{l}\text { containing secondary charge mass } \\
\text { of } 720 \mathrm{mg} \text { PETN }\end{array}$ \\
\hline
\end{tabular}

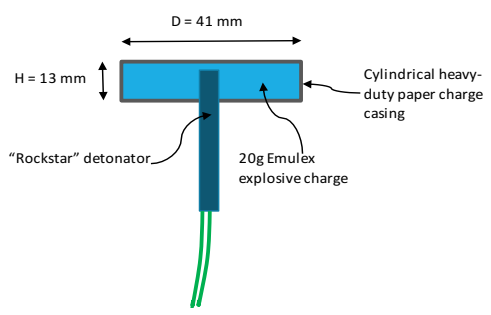

Fig. 2. Explosive charge assembly

\section{Measurement methods}

Observation on the movement of the apparatus and detonation phase during the test is by mean of optical method using Phantom V Series high-speed camera with maximum speed capability of $680000 \mathrm{fps}$. The camera was positioned approximately $5.0 \mathrm{~m}$ from the test apparatus during the blast test.

The plate acceleration is measured using PCB Piezotronic ICP shock accelerometer. The accelerometer has range up to $50000 \mathrm{G}$ 's peak $\left(490000 \mathrm{~m} / \mathrm{s}^{2}\right)$ and frequency response of $10 \mathrm{kHz}$. Adapter for accelerometer was mounted on the top face of the target plate, positioned at $80 \mathrm{~mm}$ from the centre of the target plate. Plate acceleration measurements were carried out in both air-blast and buried-in-sand tests.

\section{Test set-ups}

Experimental tests were performed according to the following test set-up;

\section{i) Air-blast test setup}

The air-blast test setup is shown in Figure 3, the apparatus is placed on $450 \mathrm{~mm}$ height concrete stands to make freespace from the ground. A $60 \mathrm{~mm}$ height polystyrene spacer block is then positioned at the centre of the target plate. This block gauged the stand-off-distance (SOD) where explosive charge is mounted on the other end of the block.

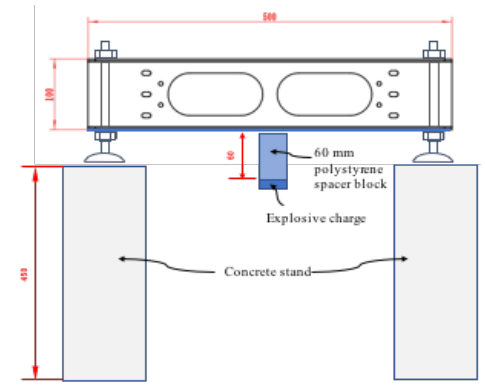

Fig. 3. Position of the apparatus and explosive charge for air-blast test setup

ii) Buried-in-sand test setup

Buried-in-sand test setup is done by placing the test apparatus on a sandy soil test bed. As shown in Figure 4, the explosive charge is buried $10 \mathrm{~mm}$ from the surface of the ground with SOD specified at $50 \mathrm{~mm}$ from the ground surface to the centre of the target plate.

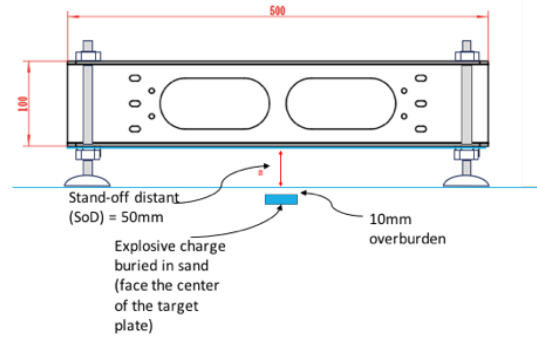

Fig. 4. Position of the apparatus and explosive charge in the buried explosive test setup

\section{Results}

\subsection{Optical observations}

High-speed camera was set to shoot at $30000 \mathrm{fps}$ and interval at $33.31 \mu \mathrm{s}$ pf. Optical observation presented in this paper is the observation that was carried out in buriedin-soil test. This is to demonstrate its correlation with detonation phases in soil which also see the effect and time of impact from soil ejecta. 
Phase 1: Detonation and early interaction with the soil.

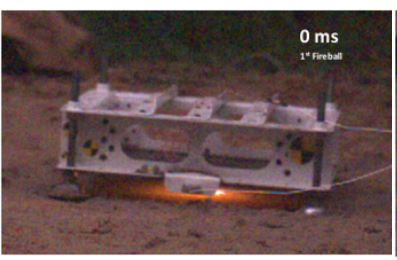

Fig. 5a

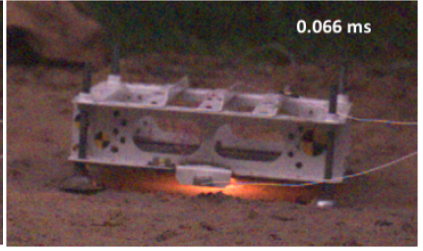

Fig. 5b
At the instance of detonation, from $0 \mathrm{~m} . \mathrm{s}-0.066 \mathrm{~m} . \mathrm{s}$ was the point at which the explosive was totally consumed by detonation wave (Fig. 5a, 5b)

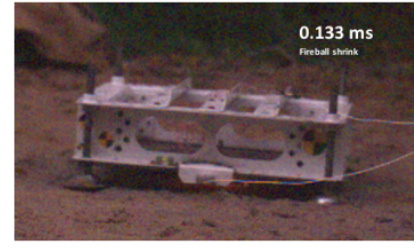

Fig. 5c

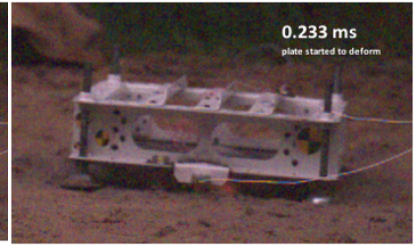

Fig. 5d
At this stage the initial expansion sent a pressure wave through the soil, at $0.133 \mathrm{~m} . \mathrm{s}$ fireball started to shrink, however at $0.233 \mathrm{~m} . \mathrm{s}$ the target plate started to deform (Fig. 5c, 5d).

Phase 2: Gas expansion.

This phase seemed to occur at $0.266 \mathrm{~m} . \mathrm{s}$, at which point wave reflected from the air-soil interface and created fissures, and target plate was seen to experience more deformation (Fig. 5c). As at $1.565 \mathrm{~m} . \mathrm{s}$, high-pressure gasses expanded out of the explosive and compressed the soil below it and forced the soil above it to evacuate at high speeds. Soil cap was ejected from the surface of the soil at supersonic velocity and at this stage the test apparatus started to translate upwards (Fig. 5f).

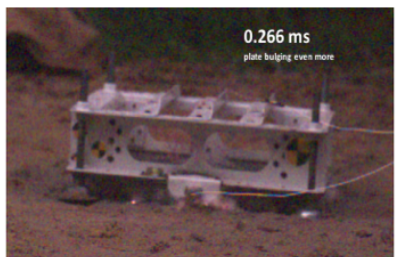

Fig. 5e

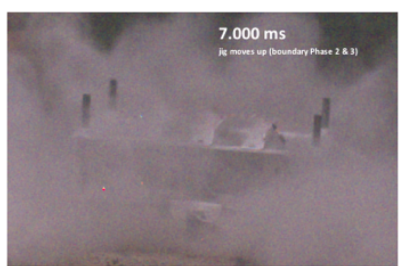

Fig. 5g

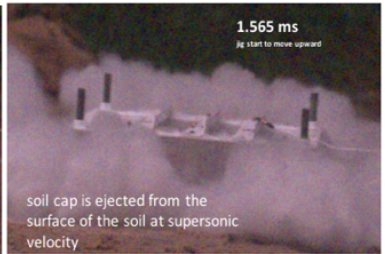

Fig. $5 f$

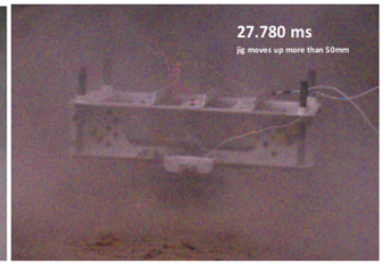

Fig. 5h
At $7.000 \mathrm{~m} . \mathrm{s}$ the test jig continued moving vertically upwards, the high pressure gas of detonation products continued to shear the region of soil surrounding it and on the cavity walls (Fig 5g). This point also marked the boundary of Phase 2 and Phase 3. At $27.780 \mathrm{~m} . \mathrm{s}$ the jig had moved up to about $50 \mathrm{~mm}$ height (Fig. 5h). This was the beginning of Phase 3, where the high-pressure gas of detonation products continued to shear the region of soil surrounding it and on the cavity walls [8].

\section{Phase 3: Soil Ejecta}

At $82.5 \mathrm{~m} . \mathrm{s}$ the jig seemed to move further upwards reaching more than $100 \mathrm{~mm}$ in height, and soil ejecta could be seen spreading out from the bottom of the jig (Fig. 5i). At this stage, a complex interaction of compression waves, rarefaction waves and soil within the cavity to further erode and eject the surrounding soil upwards at high velocity. At 160 m.s, the jig moved up to more than $200 \mathrm{~mm}$, and the spread of soil ejecta was more apparent (Fig. 5j).

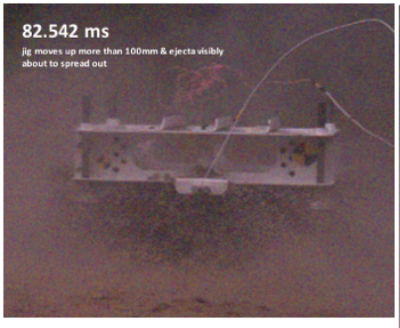

Fig. 5i

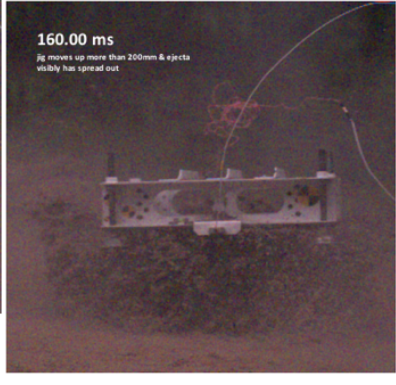

Fig. 5j

\subsection{Plate Acceleration}

The presented results are based on series of tests in airblast and buried-in-sand tests. Figure 6 shows the comparison of average plate acceleration time history recorded in air-blast and buried-in-sand tests.

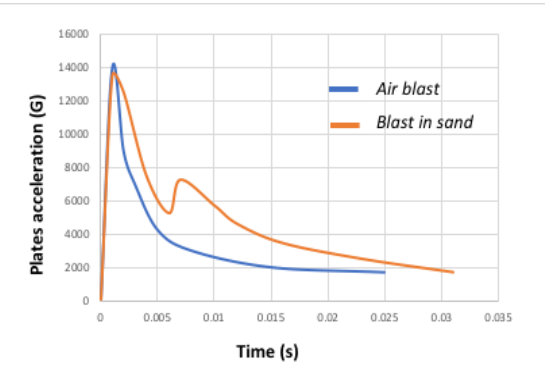

Fig. 6. Average plate acceleration - time history for air-blast and blast in sand tests

It is clear that the average peak plate acceleration in both air-blast and blast-in-sand tests reached almost $14000 \mathrm{G}$ before gradually declining. However, in blast-in-sand test, another rapid surge occurred once again when the time passed $5 \mathrm{~m} . \mathrm{s}$, it surges about $1500 \mathrm{G}$ before continuing to decrease. 
When plate acceleration in the buried-in-sand test is compared to optical observation of the same test, the time between 5 to $10 \mathrm{~m}$.s coincided with the boundary of gas expansion phase and ejecta phase, or phase 2 and 3 in phases of blast evolution in soil [9]. The plate although experiencing blast impact and acceleration, at the same time is moving upwards together with the apparatus. Although peak accelerations occurred at about $1 \mathrm{~m} . \mathrm{s}$, the optical observation showed that as the time passed 0.23 m.s, deformation of the target plate has already taken place wherein its surface was beginning to bulge, the apparatus then started to move upwards at about 1.56 m.s. In contrast with the recorded acceleration, the moment the apparatus was about to translate upwards, the plate acceleration has already begun to enter its receding phase.

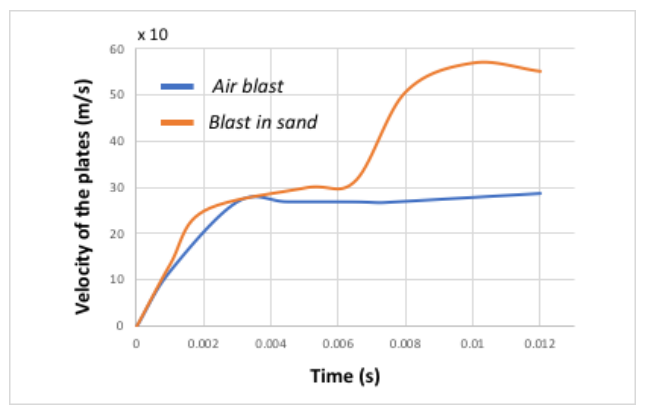

Fig. 7 Average plate velocity - time history for air-blast and blast in sand tests

Velocity of the target plate time history in air-blast tests and blast-in-sand tests are shown in Figure 7. Average velocity in air-blast tests peaked at around $3 \mathrm{~m} . \mathrm{s}$ reaching as high as $280 \mathrm{~m} / \mathrm{s}$ before it became constant. However average velocity in blast-in-sand tests show distinct pattern compared to air-blast tests, where there are two instances of velocity upsurge. The first $1 \mathrm{~m} . \mathrm{s}$ looked similar to the velocity in air-blast tests, and reached in average of $285 \mathrm{~m} / \mathrm{s}$ at $5 \mathrm{~m} . \mathrm{s}$. However, at between $6-7$ $\mathrm{m} . \mathrm{s}$, another rapid rise in velocity occurred where it peaked at around $10 \mathrm{~m} . \mathrm{s}$ with average velocity of $550 \mathrm{~m} / \mathrm{s}$.

\section{Conclusion}

Comparing peak acceleration in air-blast and blast-insand tests, the average peak acceleration in both tests did not differ much in value, wherein the average of both tests plate acceleration was around 14000 G. Nevertheless, data in terms of velocity showed better indication of the blast impact received by the target plate. Plate velocity was almost twice higher in blast-in-sand tests compared to in air-blast tests, although the first peak velocity may be slightly lower in blast-in-sand tests, the possible impact from ejecta and funnelling effect of the ground have resulted in higher peak velocity. There is a clear shoulder between two steep velocity upsurges occurring in buriedin-sand tests. The first sudden increase in velocity was similar to those of air-blast tests, which was caused by blast wave and detonation products. However, it was followed by another rapid rise after about 4 m.s of constant velocity. Correlation of optical observation with loading time of the second upsurge in plate velocity coincided with the boundary of phase 2 and phase 3 of blast evolution in soil, which was likely due to ground funnelling effect and soil ejecta impacted the target plate.

\section{References}

[1] A. Ramasamy, A. M. Hill, A. E. Hepper, A. M. Bull and J. C. Clasper, "Blast Mines: Physics, Injury Mechanisms and Vehicle Protection," Journal of Royal Army Medical Corps 155(4), pp. 58-264, 2009.

[2] S. D. Clarke, S. D. Fay, J. A. Warren, A. Tyas, S. E. Rigby and I. Elgy, "A large scale experimental approach to the measurement of spatially and temporally localised loading from the detonation of shallow buried explosives," Measurement Science and Technology 26(1), p. 26:015001, 2015.

[3] S. D. Clarke, S. D. Fay, J. A. Warren, A. Tyas, S. E. Rigby, J. J. Reay and R. Liversey, "Geotechnical causes for variation in output measured from shallow buried charges," International Journal of Impact Engineering, pp. 274-283, 2015.

[4] S. D. Clarke, J. Warren and A. Tyas, "The influence of soil density and moisture content on the impulse from shallow buried explosive charges," in International Symposium on Interaction of the Effects of Munitions with Structures, Seattle, US, 2011.

[5] S. L. Hlady, "Effect of soil parameters on land mine blast," in 18th Int. Sym. on Military Aspects of Blast and Shock (MABS18), Bad Reichenhall, Germany, 2004.

[6] J. Q. Ehrgott, S. A. Akers, J. E. Windham, D. D. Rickman and K. T. Danielson, "The influence of soil parameters on the impulse and airblast overpressure loading above surface-laid and shallow-buried explosives," Shock and Vibration 18, pp. 857-874, 2011.

[7] L. C. Taylor, R. R. Skaggs and W. Gault, "Vertical impulse measurement of mines buried in saturated sand," International Journal for Blasting and Fragmentation, Fragblast, vol. 9, pp. 19-28, 2005.

[8] V. S. Deshpande, R. M. McMeeking, H. N. Wadley and A. G. Evans, "Constitutive model for predicting dynamic interactions between soil ejecta and structural panels," Journal of the Mechanics and Physics of Solids 57, pp. 1139-1164, 2009.

[9] D. Bergeron, R. Walker and C. Coffey, "Detonation of 100-gram anti-personnel mine surrogate charges in sand: A test case for computer code validation. Technical Report 668," Defence Research Establishment Suffield, Ralston, Alberta, Canada, 1998. 